\title{
ISSUES IN INFORMATION SYSTEMS AND DESIGN: THE LIBRARIAN'S PERSPECTIVE
}

\author{
MOHAMMED M. KPAKIKO
}

Abdullahi Fodio Library, Usmanu Danfodiyo University, Sokoto, Nigeria.

\begin{abstract}
The paper is a conceptual research work which discusses the functions, characteristics, types, development stages, relevance and challenges of information system and design in libraries and information centres. It described information system and design in line with librarians' perspective. The primary aim is to contribute to the existing knowledge on the conceptual framework in designing library and information systems for library and information work. The concepts discussed and the recommendations offered will be useful to the staff and stakeholders that are involved in the design and use of information systems in Nigerian libraries and information centres.
\end{abstract}

Keywords: Information, Information system, Information system design, Librarians

\section{Introduction}

Information specialists are dealing with some sort of manual information systems. For instance, there are several hundreds of thousands of Catalogue Card entries in a Catalogue Cabinet, but if a user knows the title, subject and author of the material to access, such user can easily find the material amidst the collections in the library. Presently, information system and design is part of everyday working routines of library and information scientists employed in libraries and information centres. Freeman and Hart (2011) remarked that in the compilation of library catalogues, librarians and information specialists are engaged extensively in the designing of information systems. Currently, the task is now in the hands of librarians with information and communication technology expertise and guided by the nature of the existing technology.

Freeman and Hart (2011) pointed out that Information system in the library and information centres are set out from users' needs, which require an understanding of why and how humans seek, process and utilise information. Information systems are capable of being used for decision making and problem-solving purposes and possess a sufficient degree of flexibility so as to meet the requirements of various types of users. Maier, Mark and Rechtin (2000) asserted that designing of information systems can be taken as a problem which involves human sciences (the Social Sciences, Psychology and Linguistics) and human technology. The former as such do not provide any-made technology which could be used to support designing, but rather supplement the existing designing methods used by computer specialists, such as system methods in emphasizing the role of the user.

\section{The Concept 'Information'}

Data is often meaningless, for instance, consider the number 250214. This number could be interpreted in many ways. It could mean your car registration number, the date of a memorable event and the number of users' statistics that visit a particular library in a given period of time. This denotes that information is the meaning we attach to the data. In a similar analogy, if you are driving a car and a car travelling in the opposite direction 
flashes its lights at you, it could mean that a friend has spotted you and is saying hello; it could also mean that there is an accident further up the road. Supporting the above analogies, Doyle, (1996) asserted that the information that can be obtained from data depends on the way that the data is interpreted and the context in which it is used.

In a related opinion, Rouse (2010) described information as data that has been verified to be accurate, timely, specific and organized for a purpose. Rouse (2010) further stated that information when presented within a context that gives it meaning and relevance, can lead to an increase in understanding and decrease in uncertainty. Conceptually, Business Dictionary, (2009) described information, in its most restricted technical sense, as a sequence of symbols that can be interpreted as a message. Information can be recorded as signs or transmitted as signals. Information is any kind of event that affects the state of a dynamic system. Similarly, information is the message (utterance or expression) being conveyed. Schueber (2011) sees the concept of information as closely related to notions of constraint, communication, control, data, form, instruction, knowledge, meaning, mental stimulus, pattern, perception, representation, and especially entropy.

\section{The Concept 'Information System'}

Information system could be conceptualised as a collection of hardware, software, data, people and procedures that work together to produce quality information. A system which assembles, stores, processes and delivers information relevant to an organization (or to society) in such a way that the information is accessible and useful to those who wish to use it, including managers, staff, clients and citizens (Avison \& Fitzgerald, 2003). Buckingham et al. (2000) in Avison \& Fitzgerald (2003) described information system as a human activity (social) system which may or may not involve the use of computer systems. Ulrich and Eppinger (2000) interpreted Information system as the study of complementary networks of hardware and software that people and organizations use to collect, filter, process, create and distribute data.

Furthermore, Ulrich and Eppinger (2000) explained that Information System encompasses a variety of disciplines such as: the analysis and design of systems, computer networking, information security, database management and decision support systems. Any specific information system is aimed at supporting operations, management and decision making. In a broad sense, the term is used to refer not only to the Information and Communication Technology (ICT) that an organization uses, but also to the way in which people interact with this technology in support of business processes. According to Avison and Fitzgerald (2003), some authors make a clear distinction between information systems, computer systems, and business processes. That, Information system typically includes an ICT component but is not purely concerned with ICT, it focuses instead on the end use of information technology.

O'brien (2002) argued that information system is a special type of work system. Work system is a system in which humans and/or machines perform work (processes and activities) using resources to produce specific products and/or services for customers. An information system is a work system whose activities are devoted to processing (capturing, transmitting, storing, retrieving, manipulating and displaying) information. As such, information systems inter-relate with data systems on the one hand and activity systems on the other. 


\section{Types of Information Systems}

According to Williams (2005), there are natural and man-made systems. Natural systems may not have apparent objective, but their outputs can be interpreted as purposes. Manmade systems are with purposes that are achieved by the delivery of outputs. Their parts must be share related and must be designed.

Williams, (2005) categorized information systems into the following types:

1. Executive support system: This system assists senior management in an organization to take decision.

2. Management information system: This is concerned with internal sources of information for effective free-flow of information.

3. Decision support system: This system is specifically designed to help management take decisions in situations where there is uncertainty about the possible outcome of those decisions.

4. Knowledge management system: It helps business organizations to create and share information e.g. the creation of new knowledge and expertise.

5. Transaction processing system: Designed to process routine transactions efficiently and accurately e.g. billing system to invoices to customers, system to calculate weekly and monthly pay roll and tax payments.

6. Office automation system: Designed to improve productivity of employees who need to process data and information e.g software prepared to address particular tasks.

7. Expert information system: This guide user to find solutions to problems that would otherwise need expert advice. For instance, system designed for patient diagnosis, monitoring, selecting, designing, predicting and training.

8. Integrated information system: Combination of hardware, software and communication technologies which supports the transaction, processing and generates management information.

\section{Characteristics of Information Systems}

Most Information Systems share common characteristics. Library set up was used as an Information System with specific relevance to information work. Williams, (2005) enumerated the following characteristics of Information Systems.

i. Structure: Library as an information system is made up of several units or components working together to achieve a set objectives;

ii. It is interconnected in nature which made it to inter depend on the various divisions and units for the efficiency of work;

iii. It has a defined workflow through which sequence of activities are being carried out;

iv. It has a specific and definite goal of disseminating relevant and qualitative body of information geared towards user satisfaction;

v. It is flexible in nature because it permits future upgrade and expansion;

vi. It is dynamic in nature since its composition and workflow can be altered;

vii. System has some functions or groups of functions.

viii. The Concept of 'Information Systems Design' 
Information systems design is the process of defining the architecture, components, modules, interfaces, and data for a system to satisfy specified requirements. Systems design also involves the process of defining and developing systems to satisfy specified requirements of the user or the organisation.

According to Maier, Mark and Rechtin (2000), system analysis and design can be considered as the meta-development activity, which serves to set the stage and bound the problem. Systems design can be leveraged to set the correct balance among competing high-level requirements in the functional and non-functional analysis domains. O'brien, (2003) added that system design interacts strongly with distributed enterprise architecture, enterprise IT Architecture, and business architecture, and relies heavily on concepts such as partitioning, interfaces, personnel and roles, and deployment/operational modelling to arrive at a high-level system description. This high-level description is then further broken down into the components and modules which can be analyzed, designed, and constructed separately and integrated to accomplish the business goal.

Levin (2006) viewed systems design as cornerstones of full life cycle product and system planning. In systems design, the design functions and operations are described in detail, including output layouts, business rules, process diagrams and other documentation. The output of this stage will describe the new system as a collection of modules or subsystems. The design stage takes as its initial input the requirements identified in the approved requirements document. Levin (2006) stated that for each requirement, a set of one or more design elements will be produced as a result of interviews, workshops, and/or prototype efforts. Design elements describe the desired system features in detail, and generally include functional hierarchy diagrams, output layout diagrams, tables of business rules, business process diagrams, pseudo-code, and a complete entityrelationship diagram with a full data dictionary. These design elements are intended to describe the system in sufficient detail, such that skilled developers and engineers may develop and deliver the system with minimal additional input design.

Alter (2013) described information systems design in two perspectives:

The logical design of a system which pertains to an abstract representation of the data flows, inputs and outputs of the system. This is often conducted via modelling, using an over-abstract (and sometimes graphical) model of the actual system. In the context of systems design are included.

The physical design relates to the actual input and output processes of the system. This is laid down in terms of how data is input into a system, how it is verified and authenticated, how it is processed, and how it is displayed in physical design. The following requirements about the system are decided when designing an information system.

i. Input requirement,

ii. Output requirements,

iii. Storage requirements,

iv. Processing Requirements,

v. System control and backup or recovery.

Alter (2013) further stated that another dimension of physical portion of information systems design can generally be broken down into three sub-tasks: 
1. User Interface Design

2. Data Design

3. Process Design

1. User Interface Design is concerned with how users add information to the system and with how the system presents information back to them.

2. Data Design is concerned with how the data is represented and stored within the system.

3. Process Design is concerned with how data moves through the system, and with how and where it is validated, secured and/or transformed as it flows into, through and out of the system. At the end of the systems design phase, documentation describing the three sub-tasks is produced and made available for use in the next phase.

Physical design, in this context, does not refer to the tangible physical design of an information system. To use an analogy, a personal computer's physical design involves input via a keyboard, processing within the CPU, and output via a monitor, printer, etc. It would not concern the actual layout of the tangible hardware, which for a PC would be a monitor, CPU, motherboard, hard drive, modems, video/graphics cards, USB slots, etc. It involves a detailed design of a user and a product database structure processor and a control processor as indicated in the Levin Mark information systems development model below.
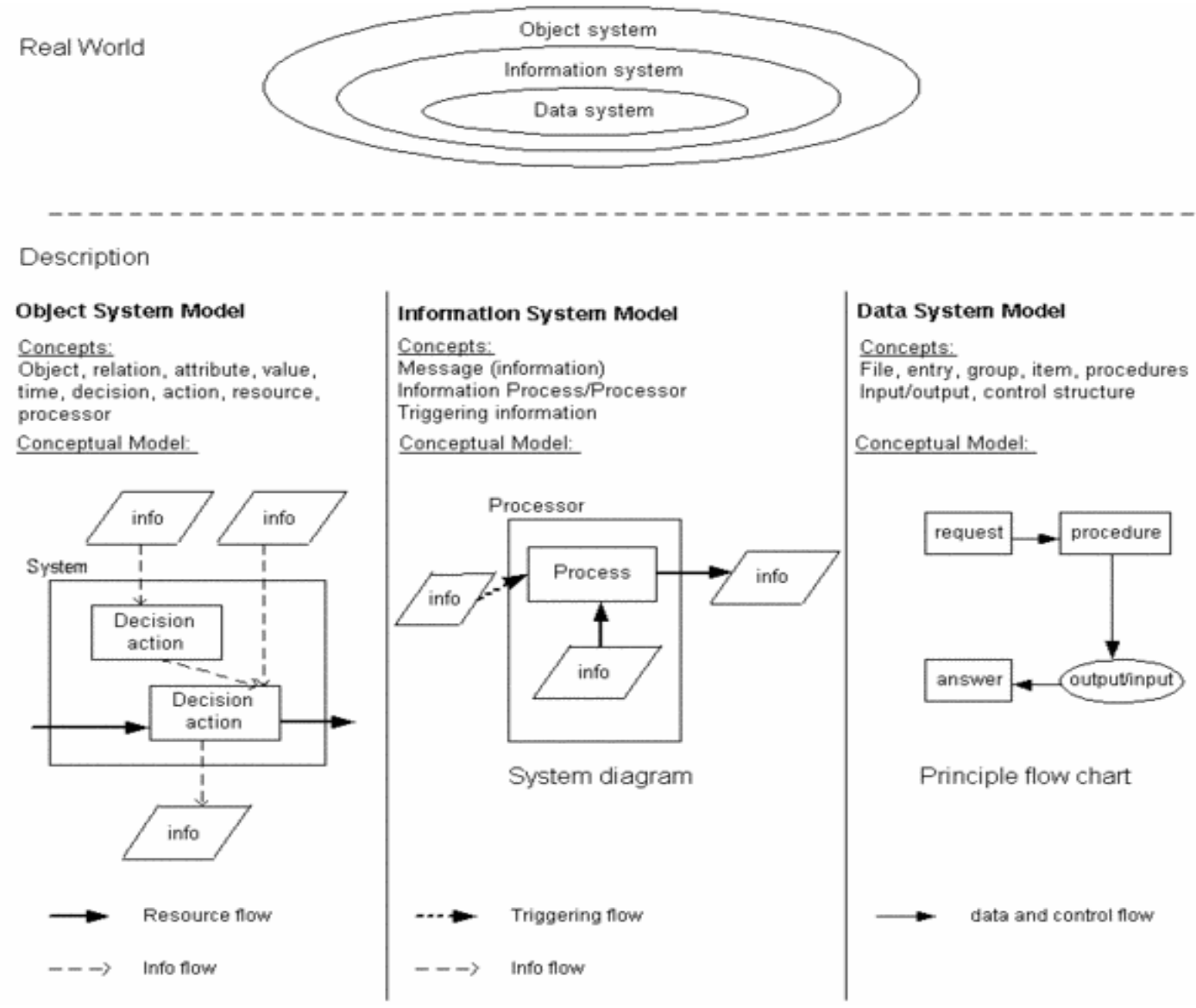

Source: $\quad$ Levin Mark (2006) Information Systems Development Model 


\section{Historical Development of Information Systems}

The history of Information systems coincides with the history of computer that began long before the modern discipline of computer science emerged in the twentieth century. Regarding the circulation of information and ideas, numerous information systems still exist today that are continuously updated to promote ethnographic approaches, to ensure data integrity, and to improve the social effectiveness \& efficiency of the whole process. In general, information systems are focused upon processing information within organizations, especially within academic institutions and business enterprises, and sharing the benefits with modern society.

Beynon-Davies (2009) revealed that several Information Science scholars have debated on the nature and foundations of Information Systems which has its roots in other disciplines such as Computer Science, Engineering, Mathematics, Management Science, Cybernetics and others. Avison and Fitzgerald (2003) stated that history of information systems development began with early computer system application development focused on the technology and on programming and technical skills rather than user and organizational needs. Systems developers were technically trained and skilled which enable them to use rule-of-thumb and personal experience. As computer use became more widespread, a backlog of computer application requests developed existing applications that are increasingly required that is tended to have expected and desirable effects.

Avison and Fitzgerald (2003) reported that in the early 1960s there was no formalized methodology for the following:

- $\quad$ basic data processing tasks

- $\quad$ batch processing

- unsophisticated technology

- $\quad$ operational level

- $\quad$ individual applications

- $\quad$ implementation by programmers

- maintenance / change problems

- $\quad$ poor documentation

- $\quad$ lack of standards and quality control

Considering the above limitations, Avison and Fitzgerald (2003) pointed out that there came the need for the analysis and design activities and personnel in the development of information systems, the need for more integrated information systems rather than piecemeal, one-off solutions, the desirability of an accepted standardized approach to development and collection of procedures, techniques, tools and documentation aids which will help the systems developers in their efforts to implement a new information system. A methodology will consist of phases, themselves consisting of sub-phases, which will guide the systems developers in their choice of the techniques that might be appropriate at each stage of the project and also help them plan, manage, control and evaluate information systems projects.

Similarly, Freeman and Hart (2011) identified the structured approaches in the development of information systems design in the 1970s, there was structured programming top-down design, "black box", basic logic constructs, structured design top- 
down, design guidelines, incremental testing, structured analysis functional decomposition, data flow diagrams and separation of logical and physical views.

In the 1980's, there was oriented-database technology, 4GLs, data analysis, data design and data management. In this phase, data becomes a corporate resource and needed for integration of applications e.g. Information Engineering (James Martin) strategic role of data independence. The success recorded here led to the following:

- $\quad$ prototyping

- $\quad$ CASE tools and development environments

- $\quad$ large database systems and 4GLs

1. decentralization

2. user participation

3. end user computing

4. soft systems approaches

In the mid-1970s and 1980s there was strategic planning approaches such as aligning information systems development with business strategy, exploitation of information technology for strategic advantage, adequate planning for IT and information systems development. System developers identify business plans and goals, strategies and evaluate current situation and developed information technology architecture. The design architecture includes information architecture, applications architecture and technical architecture.

In the 1990s, information systems development encompasses object-oriented approaches, reusability in analysis and design activities, outsourcing, enterprise planning systems (ERP), business process re-engineering, data warehouses, the Internet, intranets and extranets as well as Multimedia. In the $21^{\text {st }}$ century information system development advanced tremendously in the following areas:

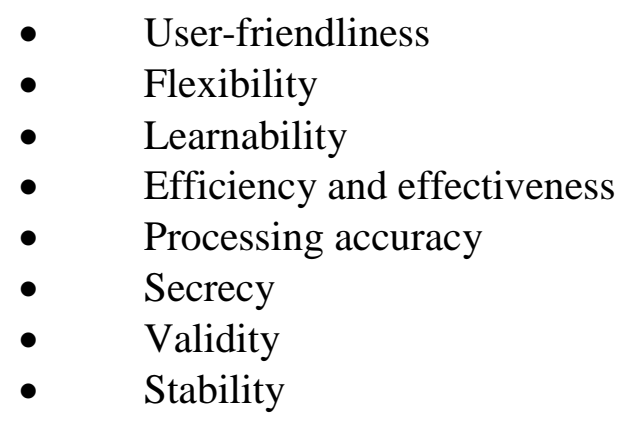

\section{Relevance of Information Systems and Design to Library and Information Services}

Globally, computers and other networking equipment are components of information system design which have been emphasized as pre- requisites for an effective information services operation in the library and information centres. Now-a-days, information system and design has become an integral part of library and information work because of their ability to perform repetitive tasks with minimal error as opposed to manual operations under conventional library and information systems that are characterized by slow speed of work, errors as well as time and energy consumption (Robertson, Swann and Newwel, 
2010). Adoption of computerised information system to the services and operation of library and information centres has become very imperative in ensuring that there is timely and adequate spread of information to end-users.

Hazzan, (2009) has aptly summarized the importance of information systems and design to library and information work that without computers, their peripherals and other communications equipment, they could not effectively process and efficiently access information. In agreement with Hazzan, (2009), this study has emphasized that adequate application of information systems equipment is inescapable for effective library operations. Also, effective use of this equipment in libraries and information centres is important in order to generate information for use. Specifically, the ability of information and communication technology systems to perform tasks at a tremendously faster rate over the manual means of doing things are responsible for the need to redefine and redesign the library and information centres.

In Nigerian library and information centres, Information System is conceived as a process of generating, processing and disseminating information and operational equipment. Information System is a combination of interdependent components that optimizes the collection, transfer and presentation of information through an integrated structure of database and information flow. When library and information centres are automated, much works can be accomplished timely with convenience, they are far more accurate in performing information processing, ability to store and provide a multi-user platform to access large volume of information resources and services at a very fast rate. To buttress the above statement, Oni, (2004) reaffirmed that library and information centres in Nigeria have witnessed transformation from being traditional to a new emerging information system that is being driven with new technologies which have introduced convenience into the ways things are done in terms of doing two or more things at the same time (multitasking), resource sharing, printing and information repacking for online access.

According to Sambo (2002), presently, library and information centres are being visualised as information systems that use formalized procedures to process data at all levels and in all functions with appropriate information, based on data from both internal and external sources that give rise to globalization. Library and information centres have become information systems under this information and communication technology age and are growing tremendously in information technology infrastructure where technical knowledge becomes available and old knowledge becomes obsolete. Sambo, (2002) classified Information systems equipment in Nigerian library and information centres into the following:

A. Electronic Equipment such as Computers, Telephone, Telex, Fax, E- Mail and Communications Satellite;

B. Printed Equipment such as files and publications (Handbooks, Bulleting, Brochures, etc.).

\section{Challenges in Information Systems and Design in Nigerian Libraries and Information Centres}

At the early stage; technology was new, costly, and so technological failure was more likely. According to Mohammed (2011), failure of information system implementations 
in Nigerian libraries and information centres are now more likely due to human or organizational problems: e.g. poor planning, poor project management, poor training, inadequate change management, poor development methods and techniques, inadequate requirements identification and specification, lack of creative design, piecemeal computerization of applications, emphasis on procedures and processes, emphasis on "how", management and strategic needs ignored, inflexibility, low productivity (application backlog).

On the other hand, there are challenges that confront information systems and design in Nigerian academic libraries and information centres as follow:

1. Some units are over worked while some are underutilized. For instance, units like Document and Africana, Serials, reference and bibliographic units receive less patronage while internet services unit and CD ROM units are always flooded with patrons.

2. Some resources in Nigerian academic Libraries and information centres with basic functions in the information work are out dated and some outlived their usefulness. This situation hampers working efficiency of the system and needs to be overhauled.

3. There is dearth of fund in Nigerian academic libraries and information centres which has adversely affected their efficiency and effectiveness since all information systems largely depends on how the system is maintained through adequate funding.

4. Poor working policy implementation brought about a serious divide between work efficiency and patron satisfaction which consequently leads to system inefficiency.

5. Poor maintenance culture have hindered the full usability of the system, because to obtain the maximum usability of the system, it must be subjected to periodic maintenance; once this culture is not in place the system functionally deteriorates.

\section{Conclusion}

Library and Information Centres in Nigeria are required to manage information systems just as all businesses must make profit. What is needed is a system that must function towards a specific direction on the route to those overall goals. Then, it is fair to elevate a well-managed information system to the same level of importance as making profit (Wilson, 2001).

It could be argued here that however well information system is being managed, without positive and efficiency, the work is synonymous to failure. On the other hand, without information systems, decisions are impossible, and success depends upon good decision making throughout the organization. Flexibility and responsiveness are paramount, and these abilities of course depend on information system as to the way it was established to collect, process and disseminate information which makes information work easier and convenient with high degree of user satisfaction. 


\section{Recommendations for Improving Information Systems and Design in Nigerian Libraries and Information Centres}

The ultimate aim of any information system is to satisfy the needs of the users. Therefore, the following measures, when adopted, will go a long way in improving information systems and designs in Nigerian libraries and information centres.

1. When designing library and information system, each components or units that forms a system should be a portion with a specialized personnel and responsibility which should operate in line with its specification to avoid over dependency.

2. For library and information system to function to its optimum expectation, the resources (human and material) should be weeded and updated from time to time to check their relevancy.

3. Organizations in which system operates should diversify their means of generating funds to keep the system running.

4. Good policies for change and improvement, such as automation, should be adequately implemented if not fully at once, but gradually, to keep to the pace of system development and modernization.

5. Information systems have working behaviour and structure and continuous usage subject them to wears and tears. Therefore, systems should be exposed to a traditional routine customisation, upgrading and maintenance.

\section{References}

Ango, R. J. and Igwe, K. N. (2011). Information and Communication Technology (ICT) Systems for Library Services. Offa: Wunmi Commercial Press.

Alter, S. (2013). "Work System Theory: Overview of Core Concepts, Extensions, and Challenges for the Future", Journal of the Association for Information Systems, 14(2): 72-121.

Avison, D.E. \& Fitzgerald, G. (2003). Information Systems Development: Methodologies, Techniques and Tools. (3rd ed), London: McGraw-Hill.

Beynon-Davies P. (2009). Business Information Systems. Palgrave: Basingstoke. Business Dictionary.com (2009). Retrieved on 08/07/2014 from http://www.inc.dictionary.com/20030501/25435.html.

Doyle, S. (1996). Information Systems for You (Revised Edition). Tonbridge Kent: Green Gate Publishing Services.

Ekwere, C. E. (1990). Evaluation of the Management Information Systems in Universities: The Case of University of Calabar, Cross River State. Unpublished Ph.D. Thesis, University of Ibadan, Ibadan. Federal Republic of Nigeria.

Freeman, P. and Hart, D. (2011). "A Science of Design for Software-Intensive Systems Computer Science and Engineering Needs an Intellectually Rigorous, Analytical, Teachable Design Process to Ensure Development of Systems. 
Hazzan, O. (2009). Information technologies and objects to learn with. Educational Technology. 39a (3): 55-59.

Hoganson, K. (2001). "Alternative Curriculum Models for Integrating Computer Science and Information Systems Analysis, Recommendations, Pitfalls, Opportunities, Accreditations, and Trends". Journal of Computing Sciences in Colleges, 17 (2): 313325.

Levin, Mark Sh. (2006). Composite Systems Decisions. New York: Springer.

Maier, M. W., and Rechtin, E. (2000), The Art of Systems Architecting, Second Edition, CRC Press: Boca Raton.

Mohammed, Z. (2011). Information Systems Analysis and Design. Unpublished Postgraduate Lecture Note. Department of Library and Information Science, Ahmadu Bello University, Zaria-Nigeria.

O'Brien, J A. (2003). Introduction to information systems: essentials for the e-business Enterprise. McGraw-Hill: Boston, MA.

Oni, F.A. (2004). Enhancing the Performance of Library Operations through appropriate Information Technology. Technology for Information Management and Service in Modern Libraries and Information Centers in Developing Countries. Madu, E.C. (ed) Ibadan: Evi Coleman Publications.

Robertson, M; Swann, J. \& New well, S.(2010). The role of networks in the diffusion of Technological Innovation. Journal of Management Studies. 33 (3): 33-359.

Rouse, H. (2010): Entrepreneurial attitude: Wodurch Wertsen Sie determinniert undeveiche Rolle Spielt die Region” Zeistschrift fur wirts sehafts geographic, 3 - 4.

Sambo, A. (2002). Management Information System and University Administration. University System News: A Quarterly Publication of NUC, Special November Edition, 11 (12 \& 16).

Schueber, M. (2011). Information Management Strategy Formation in Northern Development NGOs. Institute for Development Policy and Management, University of Manchester. Retrieved From http://idpm.man.ac.uk/wp/di/index.html on the 27th September, 2014.

Ulrich, Karl T. and Eppinger, Steven D. (2000), Product Design and Development, Second Edition. Boston: Irwin McGraw-Hill.

Wilson, D. A. (2001). Managing information (2nd ed.). Woburn: Butterworth Heinemann.

Williams, S. (2005). Using Information Technology: A Practical Introduction to Computer and Communications (6th ed.). New York: Mc Graw Hill. 